\title{
Projeto Cuidar no rastreamento da doença renal crônica
}

\author{
Thais Michele de Medeiros Riguete, Márcio Henrique Scoltelano
}

\begin{abstract}
Resumo
A doença renal crônica (DRC) é caracterizada por alterações na taxa de filtração glomerular e/ou presença de lesão parenquimatosa mantidas por pelo menos três meses. Ela é considerada um problema de saúde pública no mundo e no Brasil tem aumentado a incidência e a prevalência da perda da função renal. Nesse contexto é imprescindível o diagnóstico precoce da doença para diminuir sua progressão, além de uma maior atenção aos fatores de risco associados como o diabetes mellitus e a hipertensão Arterial. Rastrear os fatores de risco associados à doença renal crônica, alertar a população sobre a importância do cuidado junto aos profissionais de saúde e a manutenção de hábitos de vida saudáveis, além de permitir a troca de experiência entre os membros da equipe. A Liga Acadêmica de Prevenção às Doenças Renais (Pré-Renal) da Universidade Federal de Juiz de Fora realiza o projeto de extensão chamado Projeto Cuidar no bairro de São Pedro localizado na cidade de Juiz de Fora - MG. A Pré-Renal é composta por discentes das áreas de medicina, enfermagem, nutrição, educação física, odontologia, serviço social, psicologia, fisioterapia e farmácia que realizam visitas domiciliares nas quais são feitos diversos procedimentos, como o teste de uroanálise por meio de uma fita reagente, aferição de pressão arterial, altura, circunferência da cintura, peso e aplicação do questionário multidisciplinar que contém informações básicas de identificação bem como perguntas acerca dos fatores de risco associados à doença renal crônica, após todos os participantes assinarem o Termo de Consentimento Livre e Esclarecido (TCLE). Por meio do Projeto Cuidar da Liga Acadêmica de Prevenção às Doenças Renais foi possível realizar o rastreamento dos fatores de risco associados à doença renal crônica em 859 moradores entre os anos de 2013 e 2015. O projeto também permitiu a troca de conhecimentos e experiências entre os membros da equipe, além das orientações à população sobre a busca pelo serviço de saúde, nos indivíduos que se encontravam em risco, e das orientações acerca da manutenção de hábitos de vida saudáveis. Através do Projeto Cuidar é possível notar a importância das ações que visam o rastreio precoce dos fatores de risco associados à doença renal crônica e, além disso, ele apresenta boa aceitação da população por também ser uma ferramenta de educação em saúde.
\end{abstract}

Descritores: Doença renal crônica; Liga acadêmica; Rastreamento. 